\title{
Sources of Adult Mesenchymal Stem Cells Applicable for Musculoskeletal Applications - A Systematic Review of the Literature
}

\author{
R. Mafi ${ }^{1}$, S. Hindocha ${ }^{*}, 2,3$, P. Mafi ${ }^{1}$, M. Griffin ${ }^{2}$ and W.S. Khan ${ }^{4}$ \\ ${ }^{I}$ The Hull York Medical School, Hertford Building, Hull, HU6 7RX, UK \\ ${ }^{2}$ Manchester Interdisciplinary Biocentre, University of Manchester, 131 Princess Street, M17DN, UK \\ ${ }^{3}$ Department of Plastic Surgery, Whiston General Hospital, Liverpool, L355DR, UK \\ ${ }^{4}$ University College London Institute of Orthopaedics and Musculoskeletal Sciences, Royal National Orthopaedic \\ Hospital, Stanmore, Middlesex, HA7 4LP, UK
}

\begin{abstract}
Mesenchymal stem cells (MSCs) were first discovered by Friedenstein and his colleagues in 1976 from bone marrow. The unique property of these cells was their potential to develop into fibroblastic colony forming cells. Since Friedenstein's discovery of these cells the interest in adult MSCs has been progressively growing. Nowadays MSCs are defined as undeveloped biological cells capable of proliferation, self renewal and regenerating tissues. All these properties of MSCs have been discovered in the past 35 years. MSCs can play a crucial role in tissue engineering, organogenesis, gene therapy, transplants as well as tissue injuries. These cells were mainly extracted from bone marrow but there have been additional sources for MSCs discovered in the laboratories including: muscle, dermis, trabecular bone, adipose tissue, periosteum, pericyte, blood, synovial membrane and so forth. The discovery of the alternative sources of MSCs helps widen the application of these cells in different areas of medicine. By way of illustration, they can be used in various therapeutic purposes such as tissue regeneration and repair in musculoskeletal diseases including osteonecrosis of femoral head, stimulating growth in children with osteogenesis imperfecta, disc regeneration, osteoarthritis and duchenne muscular dystrophy. In order to fully comprehend the characteristics and potential of MSCs future studies in this field are essential.
\end{abstract}

Keywords: Mesenchymal stem cells, muscular dystrophy, musculoskeletal applications, tissue engineering.

Thirty five years ago Friedenstein et al. discovered mesenchymal stem cells (MSCs) in the bone marrow where he observed a certain population of cells that developed into fibroblastic colony forming cells (CFU-F) [1]. MSCs account for a very small ratio of the bone marrow and it has been estimated that $1 / 10000$ to $1 / 100000$ of the bone marrow nuclear cells are MSCs [2,3]. Since the ground breaking discovery of these cells, the interest in adult MSCs has been growing and other sources of the adult MSCs have been identified by scientists. The new sources of adult MSC can be used for various therapeutic purposes such as tissue regeneration and repair in musculoskeletal diseases [4]. Despite their therapeutic and clinical significance, there are no articles bringing together and comparing the sources of MSCs and their various applications in musculoskeletal conditions. In this systematic review, studies have been searched for different sources of adult MSCs as well as the recent musculoskeletal applications using adult MSCs. These studies were predominantly searched using AMED, CINAHL, EMBASE, Medline, PubMed and ZETOC. The aim of this study is to summarize all the available literature relating to sources of adult MSCs and their application in musculoskeletal diseases.

\footnotetext{
*Address correspondence to this author at the Department of Plastic Surgery, Whiston Hospital, Warrington Road, Liverpool, L35 5DR, UK; Tel: 01244366265; Fax: 01244366277; E-mail: hindocha2001@yahoo.com
}

Stem cells are defined as undeveloped biological cells capable of proliferation, self renewal, conversion to differentiated cells, and regenerating tissues. There are two main types of stem cells in mammals [5]; embryonic stem cells (ESC) are pluripotent cells derived from the inner cell mass of blastocyts which are formed several days after an egg is fertilised, and nonembrionic stem cells (non-ESC) also known as adult stem cells as they are usually attained from the bone marrow of adults. There are two types of stem cells from this source: Haemopoietic, that differentiate into blood cells, and MSCs. Less mature tissue sources including umbilical cord blood, placenta and fetal somatic tissues are ranked among the non-ESCs. Furthermore, the fetal stem cells (FSCs) are regarded as an intermediate cell type between ESCs and adult stem cells. FSCs are obtained from the gonads in the first trimester of development $[5,6]$.

It has been more than 130 years that the existence of nonhematopoietic stem cells was proposed by the German pathologist Cohneim. He suggested that bone marrow can aid the wound healing process in various peripheral tissues $[7,8]$. This theory was confirmed by Friedenstein in the 1970 's. He discovered that the bone marrow consisted of fibroblastoid cells with clonogenic potential in vitro which are capable of forming colonies (CFU-F). Furthermore, Friedenstein proved that it was achievable to regenerate heterotopic bone tissue in different transplants. This way he provided evidence in support of the self renewal potential of these cells [1]. Ever since, numerous scientists have 
confirmed those findings and have expanded on them by showing that the cells isolated by Friedenstein were also present in human bone marrow. Moreover, they demonstrated that these cells could be differentiated in vitro into cells with mesenchymal lineages such as adiopocytes, chondrocytes, myoblasts and osteoblasts [9]. Therefore, cells isolated by Friedenstein were named MSCs by Caplan and colleagues [10].

After the discovery of the MSCs, it has progressively become clear that these cells could be the basis for a natural system of tissue repair [11]. In various studies MSCs have proven to be an effective therapeutic agent in experimental models of tissue injuries [12-14]. According to Prockop et $a l$. in the majority of these studies there was little correlation between therapeutic efficacy and engraftment efficiency. Consequently, the ability to repair is secondary to the secretion of soluble factors by MSCs which alter the tissue microenvironment [7]. In other words, according to Caplan and colleagues MSCs may provide the so called 'trophic activity' [10]. It has been demonstrated that MSCs in vitro produce a variety of factors that are capable of manipulating a broad range of biological functions. Among the most important are angiogenesis, secretion of neuroregulatory peptides and cytokines that have crucial role in inflammation and repair [10].

Further investigations in the biology of MSCs in the in vivo setting will provide an important insight into cellular mechanisms of angiogenesis, bone development, hematopoiesis and vasculogenesis. Despite numerous studies which correlate CFU-Fs to bone mass there is still no robust evidence indicating that MSCs are the skeletal stem cells $[15,16]$. Significant information is gathered concerning the use of MSCs for tissue engineering purposes. Scientists identified various modalities of expanding bone marrow as well as adipose tissue MSCs while retaining their multipotency $[7,10]$. These cells have only been experimented on animal models to form tissues such as bone and cartilage at specific sites thus, there is no MSC technology for humans available [7].

According to Phinney et al., if the MSCs develop into a natural system of tissue repair then it is essential to know how these cells are able to reach the site of injury. Chamberlian et al. point out the chemokines including SDF1 and its cognate receptor CXCR4 to have a significant role in guiding MSCs to sites of injury [17]. A more recent study by Belema-Bedada et al. suggests that the cytokine receptor CCR2 and the intercellular adaptor molecule FROUNT serve in a similar way to SDF1 for taking the bone marrow derived MSCs to various sites for repair [18]. Despite these studies, there is not sufficient information regarding the mobilization of the MSCs from the bone marrow. Rochefort et al. claim that MSCs can be perceived in circulating blood and the circulating pool can increase by exposure to chronic hypoxia [19]. However, the precise mechanism of this phenomenon remains an enigma.

MSCs can be distinguished from the hematopoietic stem cells (HSCs) by their cell surface antigens which create a phenotypic separation from HSCs. Therefore identification of cell-specific cell surface markers on MSCs is of great importance. Numerous cell-surface antigens expressed by the MSCs have been identified but only very few scientists managed to establish a phenotypic characterization of MSCs in vivo [20].

In 1980's, Simmons et al. managed to isolate an antibody called STRO1 that could recognize the cell surface antigen in human MSCs. The cell population identified by this antibody were referred to as STRO-1 positive cells and were able to generate CFU-Fs and differentiate into multiple mesenchymal lineages in vitro [21]. More recently it was reported that by positive selection for VCAM/CD106 the degree of homogeneity of the STRO-1 positive cells could be more enhanced [22]. In addition to that, MCAM/CD146 positive cells isolated from BM-MSCs hold on plastic in vitro and are clonogenic. Other properties of these cells include self-renewal in vitro, generating bone and a hematopoietic supportive microenvironment in transplants done in mice [23]. The relationship between the $\mathrm{MCAM} / \mathrm{CD} 146$ positive cells and the ones reported by Simmons et al. needs to be elucidated.

Simmons and colleagues have also identified a bone marrow pool of CD45 (-) CD31 (-) cells which appear to consist of MSCs [24, 25]. CD45 and CD31 are panhematopoietic and endothelial cell markers respectively and were broadly used in this study to negatively select for hematopoietic as well as endothelial cells. Interestingly, a study led by Rogers et al. has also shown that a subset of CD45 (+) Lin (-) bone marrow cells could differentiate in vivo into different cells including endothelial cells, osteoblasts, muscle cells and natural cells. This finding contradicts the nature of $\mathrm{CD} 45$ as a marker of hematopoietic cells and can be used to redefine the boundary between HSCs and MSCs.

In the previous decade, MSCs have been used by scientists for gene therapy in experimental models and to treat certain conditions including osteogenesis imperfecta in humans. In order to use MSCs as permanent therapeutic agents in the future, more research is required [26, 27].

One of the most significant features of MSCs that is worth considering is their extraordinary and unexplained immunomodulartory properties. It has been reported that the adult MSCs express intermediate levels of class I major histocompatibility complex (MHC) proteins but no class II MHC proteins. Therefore, this phenotype is classified as non-immunogenic, which indicates that no immunosuppression is required in a transplant into an allogenic host [28]. Further studies have shown that MSCs have immunosuppressive properties by modulating specific T-cell functions in vitro and can be translated into in vivo setting in experimental models $[29,30]$.

\section{MATERIALS AND METHODS}

The relevant articles for this review were searched primarily from the electronic data bases AMED, ASSIA (CSA Illumina), CINAHL (EBSCO), Conference Proceedings Citation Index: Science (ISI) on Web of Knowledge, EMBASE, Medline, PREMEDLINE In-Process $\&$ Non-Indexed Citations (OvidSP), PsycINFO (OvidSP), PubMed, Science Citation Index (ISI) on Web of Knowledge, Social Sciences Citation Index (ISI) on Web of Knowledge and Cochrane Library (Wiley) and ZETOC. The following key words were used for citing the appropriate articles: mesenchymal stem cells, stem cells, MSC 
applications, musculoskeletal applications, tissue engineering and muscular dystrophy.

The following inclusion criteria were used to select relevant studies: A) Identified sources of MSCs in adult humans, B) Contained information about the applicability of MSCs in musculoskeletal conditions. C) Articles using animal MSCs for human applications. Articles which were excluded: A) did not include MSCs B) Involved stem cells not found in adults, e.g. embryonic stem cells, C) Failed to refer to potential uses of MSCs in musculoskeletal diseases. Out of 151 articles and studies that were viewed 78 were found relevant and suited the inclusion criteria.

\section{RESULTS}

The relevant information from the included articles is summarized in Tables $\mathbf{1}$ and $\mathbf{2}$.

As presented in Table 1, new sources for adult MSCs have been found since 1976. Adult stem cells have the ability to differentiate into more than one cell type, but unlike the embryonic stem cells they are often restricted to certain types or 'lineages' $[51,52]$. MSCs have the potential to differentiate into chondrocytes, osteoblasts, adipocytes, fibroblasts, marrow stroma, and other tissues of mesenchymal origin [4]. According to the studies summarized in Table 1, the MSCs derived from the bone marrow have a higher transdifferentiation ability than Mesenchymal cells of different origin which can differentiate into 11 types of cells. The bone marrow aspirate is currently considered the most enriched and accessible source of MSCs but according to Tuan et al. [4]. An alternative source such as trabecular bone could take its place, in view of recent efficient isolation of multipotential cells from this tissue [4]. A recent study by Sart et al. [53] argues that ear MSCs bear the characteristics of progenitor cells because of their ability to be differentiated into the three lineages of osteocytes, adipocytes and chondrocytes. Furthermore, it was found that Ear-MSCs had a threefold higher cell growth rate compared to bone marrow derived MSCs. According to Shi et al. [54] there are also other sources for MSCs that have been discovered such as umbilical cord blood, amniotic fluid, placenta, dental pulp, tendons, though the complete equivalency of such populations has not been formally demonstrated and it is not for certain what lineages they can differentiate into.

\section{DISCUSSION}

In this systematic review we managed to look at various studies that discussed the nature and source of the MSCs and reviewed the application of these cells for organogenesis and tissue engineering for numerous diseases. Apart from summarizing various sources of the adult MSCs their lineage differentiation potentials have been pointed out as well. With regards to studies in Table $\mathbf{1}$, MSCs derived from the bone marrow have the most differentiation potential among the rest, now the question rises whether one should only rely on bone marrow derived MSCs for therapeutic applications?

According to the literature reviewed, it can be deduced that there is great discrepancy whether bone marrow derived

Table 1. The Various Sources of Adult MSCS as well as their Multilineage Differentiation

\begin{tabular}{|c|c|c|}
\hline Adult MSCs Sources & Multilineage Differentiation Potential & Authors \\
\hline Bone marrow & $\begin{array}{c}\text { Adipocyte } \\
\text { Astrocyte } \\
\text { Cardiocyocyte } \\
\text { Chondrocyte } \\
\text { Hepatocyte } \\
\text { Mesangial cell } \\
\text { Muscle } \\
\text { Neuron } \\
\text { Osteoblast } \\
\text { Stromal cell } \\
\text { Embryonic tissue }\end{array}$ & $\begin{array}{c}\text { Pittenger et al. [31] } \\
\text { Kopen et al. [32] } \\
\text { Fukuda et al. [33] } \\
\text { Johnstone et al. [34] } \\
\text { Petersen et al. [35] } \\
\text { Ito et al. [32] } \\
\text { Ferrari et al. [36] } \\
\text { Azizi et al. [37] } \\
\text { Pittenger et al. [31] } \\
\text { Majumdar et al. [38] } \\
\text { Jiang et al. [39] }\end{array}$ \\
\hline Muscle & $\begin{array}{c}\text { Adipocyte, Myotubes } \\
\text { Endothelial Cell, neuron } \\
\text { Chondrocyte } \\
\text { Osteocyte }\end{array}$ & $\begin{array}{c}\text { Wada et al. [40] } \\
\text { Qu-Petersen et al. [35] } \\
\text { Adachi et al. [41] } \\
\text { Bosch et al. [42] }\end{array}$ \\
\hline Dermis & Adipocyte, chondrocyte, osteoblast & Young et al. [43] \\
\hline Trabecular bone & Adipocyte, chondrocyte, muscle, osteoblast & Noth et al. [44] \\
\hline Adipose tissue & $\begin{array}{l}\text { Chondrocyte, muscle } \\
\text { Osteoblast, Stromal cell }\end{array}$ & $\begin{array}{c}\text { Zuk et al. [45] } \\
\text { Gronthos et al. [46] }\end{array}$ \\
\hline Periosteum & Chondrocyte, osteoblast & Nakahara et al. [47] \\
\hline Pericyte & Chondrocyte & Diefenderfer et al. [48] \\
\hline Blood & Adipocyte, fibroblast, osteoblast, osteoclast & Zvaifler et al. [49] \\
\hline Synovial membrane & Adipocyte, chondrocyte, muscle, osteoblast & De Bari et al. [50] \\
\hline
\end{tabular}


Table 2. The Use of Different Sources of MSCs in Musculoskeletal Applications

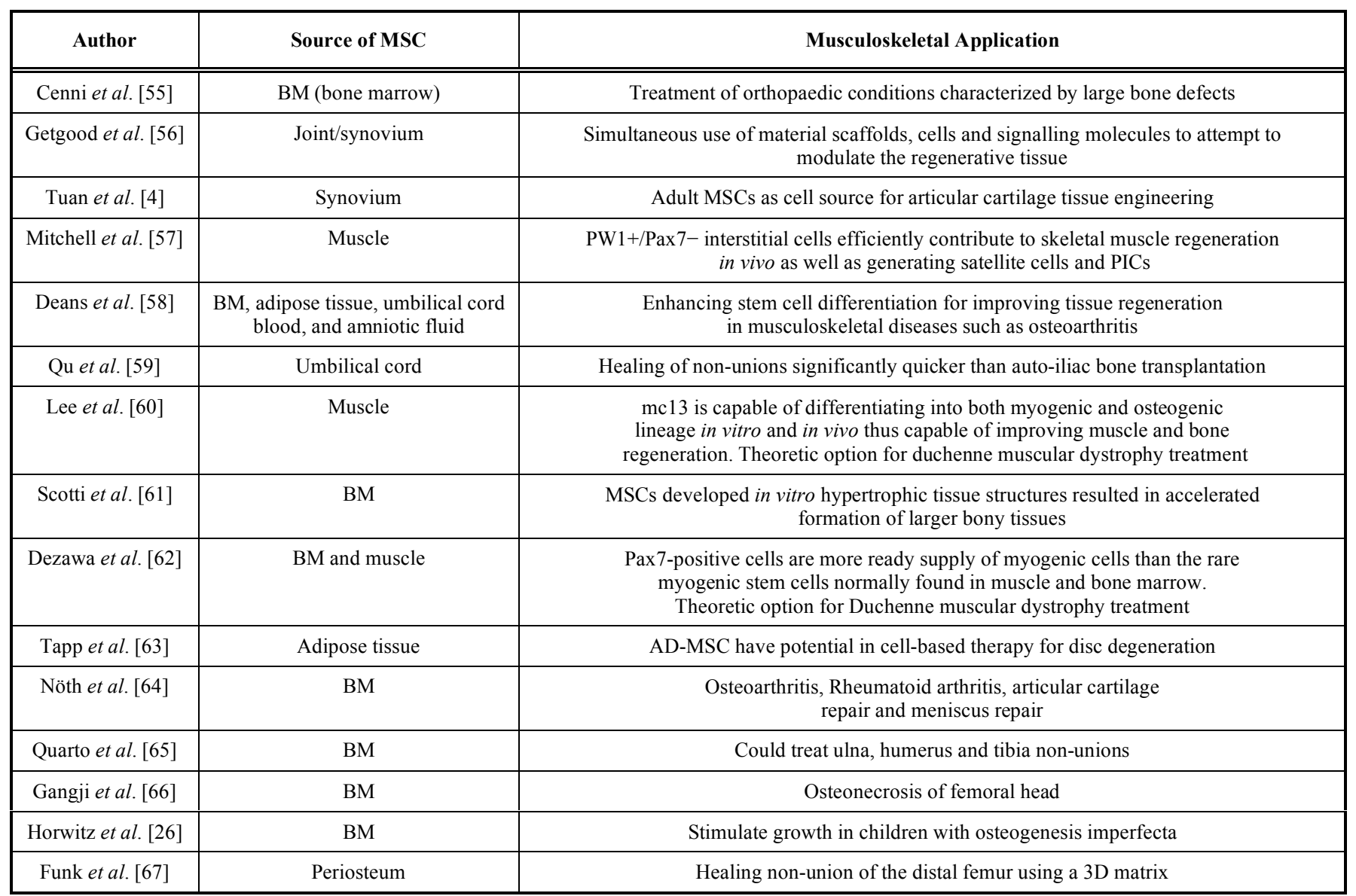

MSCs is the best available source to be used or other sources of adult MSCs are as good or even better. By taking the information of Table 2 into consideration it can be deduced that mainly muscle derived MSC's are used for muscle related applications and bone marrow derived $\mathrm{MSC}$ are the preferred choice for degenerative bone diseases.

When comparing different sources of MSCs, each source has its advantages and draw backs. By the way of illustration, bone marrow derived stem cells have high multilineage differentiation but do not have the greatest cell growth rate as Sart et al. [53] in his recent study shows that ear derived MSCs have a threefold higher cell growth rate compared to bone marrow derived MSCs. MSCs from umbilical cord blood have fewest colonies after they have been isolated, but they showed a much higher proliferation capacity compared to bone marrow derived MSCs. In addition to that, adipose tissue derived MSCs showed to have greater number of colonies to bone marrow derived MSC [58]. Even though bone marrow is easily accessible for musculoskeletal applications some studies used other sources of adult MSCs. For instance $\mathrm{Qu}$ et al. demonstrated that MSCs extracted from human umbilical cord healed nonunion significantly quicker than auto-iliac bone transplantation [59]. In addition to that Funk et al. states that periosteum derived stem cells can aid to heal non-union of the distal femur using a 3D matrix. Despite being the first MSCs discovered, bone marrow derived MSCs might not be the most suitable sources of MSCs for musculoskeletal applications. Furthermore, It is interesting to note that in
Tuan et al. review [4] and shi et al. [54] they did not consider umbilical cord blood, amniotic fluid, placenta, dental pulp and tendons as sources of adult MSCs even though MSCs can be extracted from them, due to the lack of robust scientific evidence [4].

Numerous studies over the years have shown that MSCs could potentially become the basis for a powerful 'natural system of tissue repair' [68]. MSCs have demonstrated their ability to serve as effective therapeutic agents in variety of experimental models of different tissue injuries [13]. Horwitz et al. [26], Gangji et al. [66] and Quarto et al. [65] managed to use bone marrow derived MSCs for aiding osteonecrosis of femoral head and stimulating growth in children with osteogenesis imperfecta. Other studies [60, 62] suggest that BM-MSCs as well as muscle derived MSCs can be used to regenerate bone and muscle in Duchenne muscular dystrophy. One should not overlook the fact that these studies have been successful on animals such as rats and dogs but no trials on humans have been done. A further study combines sand rat AD-MSCs with human annulus cells as possible option for cell-based autologous disc regeneration [63].

For future advances in MSCs in the field of regeneration and tissue engineering it is important to know the exact nature of these cells. Therefore, focusing on the cellular and genetic signature of MSCs is required. One way to achieve this is by investigating other populations of stem cells and techniques such as flow cytometry to analyze specific cell- 
surface markers [4]. Furthermore, more specific information is required concerning the endogenous function in the adult MSCs' tissues to give a better understanding of their true potential for clinical uses. Learning about the role of these cells in organogenesis is required in order to adjust in vivo repair and regeneration processes without the necessity for in vitro expansion.

Developing a model that tests for the ability of MSCs to self-renew, proliferate and differentiate in vivo could aid to investigate more in characterization of the MSCs. By way of illustration, a test that is becoming more popular is the murine intratibial injection of MSCs and characterization of their role in bone homeostasis and fracture repair [69].

An additional achievement in this field would be to identify certain pharmacological tools in order to expand in vivo and in vitro the mesenchymal stem cell pool. There have been investigations in this field and tools such as proteosome inhibitor Velcade have been reported to expand the MSC pool in a murine model in vivo [70,71].

In order to identify the appropriate pharmacological tools detailed analysis of the complex network of signalling pathways and regulatory cells that control the ability of MDCs for self-renewal, proliferation and predominantly differentiation is required. The identification of this network should not be underestimated as it will reveal the rules that govern the size of the MSC pool in vivo. This will eventually allow appropriate pharmacological interventions which would assist in the different applications of the MSCs in various diseases. To gain insight into the molecular mechanisms of the MSCs a global gene expression profiling approach could prove of great assistance [72-77].

Eventually, it is not for certain how valuable the in vivo analysis of genetically modified experimental models could be for humans. According Riminucci et al. human diseases such as fibrous dysplasia can broaden our understanding of MSCs, for instance analysis of Gs[alpha] signalling pathway in this disease, which involves early cells of osteoblast lineage in mosaic individuals, can be a model worth considering [78].

\section{CONCLUSION}

Adult MSCs have various sources and present an exciting progenitor cell source for applications of tissue engineering and regenerative medicine. Bone marrow was the first source of adult MSC but in recent years other sources have been identified. Among the most significant are muscle, skin, adipose tissue, synovial membrane, dermis, trabecular bone, periosteum, pericyte and blood. There is also potential evidence that MSCs derived from adult tissues can aid certain musculoskeletal diseases such as osteonecrosis of femoral head, stimulating growth in children with osteogenesis imperfecta, disc regeneration, osteoarthritis and duchenne muscular dystrophy. In order to fully understand the potential of these cells future studies should be directed to ascertain their cellular characteristics and the endogenous function of MSCs in normal and abnormal tissues.

\section{ACKNOWLEDGEMENT}

None declared.

\section{CONFLICT OF INTEREST}

None declared.

\section{REFERENCES}

[1] Friedenstein AJ, Chailakhjan RK, Lalykina KS. The development of fibroblast colonies in monolayer cultures of guinea-pig bone marrow and spleen cells. Cell Tissue Kinet 1970; 3(4): 393-403.

[2] Castro-Malaspina H, Gay RE, Resnick G, et al. Characterization of human bone marrow fibroblast colony-forming cells (CFU-F) and their progeny. Blood 1980; 56(2): 289-301.

[3] Civin CI, Trischmann T, Kadan NS, et al. Highly purified CD34positive cells reconstitute hematopoiesis. J Clin Oncol 1996; 14(8): 2224-33.

[4] Tuan RS, Boland G, Tuli R. Adult mesenchymal stem cells and cell-based tissue engineering. Arthritis Res Ther 2003; 5(1): 32-45.

[5] Tuch BE. Stem cells--a clinical update. Aust Fam Physician 2006; 35(9): 719-21.

[6] Svendsen C. Stem cells: hype or hope? Drug Discov Today 2002; 7(8): 455-6.

[7] Prockop DJ. "Stemness" does not explain the repair of many tissues by mesenchymal stem/multipotent stromal cells (MSCs). Clin Pharmacol Ther 2007; 82(3): 241-3.

[8] Prockop DJ. Marrow stromal cells as stem cells for nonhematopoietic tissues. Science 1997; 276(5309): 71-4.

[9] Bianco P, Robey PG, Simmons PJ. Mesenchymal stem cells: revisiting history, concepts, and assays. Cell Stem Cell 2008; 2(4): 313-9.

[10] Caplan AI. Adult mesenchymal stem cells for tissue engineering versus regenerative medicine. J Cell Physiol 2007; 213(2): 341-7.

[11] Phinney DG, Prockop DJ. Concise review: mesenchymal stem/multipotent stromal cells: the state of transdifferentiation and modes of tissue repair--current views. Stem Cells 2007; 25(11): 2896-902.

[12] Ortiz LA, Dutreil M, Fattman C, et al. Interleukin 1 receptor antagonist mediates the antiinflammatory and antifibrotic effect of mesenchymal stem cells during lung injury. Proc Natl Acad Sci USA 2007; 104(26): 11002-7.

[13] Kunter U, Rong S, Djuric Z, et al. Transplanted mesenchymal stem cells accelerate glomerular healing in experimental glomerulonephritis. J Am Soc Nephrol 2006; 17(8): 2202-12.

[14] Minguell JJ, Erices A. Mesenchymal stem cells and the treatment of cardiac disease. Exp Biol Med (Maywood ) 2006; 231(1): 39-49.

[15] Bonyadi M, Waldman SD, Liu D, Aubin JE, Grynpas MD, Stanford WL. Mesenchymal progenitor self-renewal deficiency leads to age-dependent osteoporosis in Sca-1/Ly-6A null mice. Proc Natl Acad Sci USA 2003; 100(10): 5840-5.

[16] Hilton MJ, Tu X, Wu X, et al. Notch signaling maintains bone marrow mesenchymal progenitors by suppressing osteoblast differentiation. Nat Med 2008; 14(3): 306-14.

[17] Chamberlain G, Fox J, Ashton B, Middleton J. Concise review: mesenchymal stem cells: their phenotype, differentiation capacity, immunological features, and potential for homing. Stem Cells 2007; 25(11): 2739-49.

[18] Belema-Bedada F, Uchida S, Martire A, Kostin S, Braun T. Efficient homing of multipotent adult mesenchymal stem cells depends on FROUNT-mediated clustering of CCR2. Cell Stem Cell 2008; 2(6): 566-75.

[19] Rochefort GY, Delorme B, Lopez A, et al. Multipotential mesenchymal stem cells are mobilized into peripheral blood by hypoxia. Stem Cells 2006; 24(10): 2202-8.

[20] Ratajczak MZ, Zuba-Surma EK, Machalinski B, Kucia M. Bonemarrow-derived stem cells--our key to longevity? J Appl Genet 2007; 48(4): 307-19.

[21] Simmons PJ, Torok-Storb B. Identification of stromal cell precursors in human bone marrow by a novel monoclonal antibody, STRO-1. Blood 1991; 78(1): 55-62.

[22] Gronthos S, Zannettino AC, Hay SJ, et al. Molecular and cellular characterisation of highly purified stromal stem cells derived from human bone marrow. J Cell Sci 2003; 116(Pt 9): 1827-35.

[23] Sacchetti B, Funari A, Michienzi S, et al. Self-renewing osteoprogenitors in bone marrow sinusoids can organize a hematopoietic microenvironment. Cell 2007; 131(2): 324-36.

[24] Lundberg P, Allison SJ, Lee NJ, et al. Greater bone formation of Y2 knockout mice is associated with increased osteoprogenitor numbers and altered Y1 receptor expression. J Biol Chem 2007; 282(26): 19082-91.

[25] Short B, Brouard N, Occhiodoro-Scott T, Ramakrishnan A, Simmons PJ. Mesenchymal stem cells. Arch Med Res 2003; 34(6): 565-71. 
[26] Horwitz EM, Gordon PL, Koo WK, et al. Isolated allogeneic bone marrow-derived mesenchymal cells engraft and stimulate growth in children with osteogenesis imperfecta: Implications for cell therapy of bone. Proc Natl Acad Sci USA 2002; 99(13): 8932-7.

[27] Nixon AJ, Goodrich LR, Scimeca MS, et al. Gene therapy in musculoskeletal repair. Ann N Y Acad Sci 2007; 1117: 310-27.

[28] Le BK, Ringden O. Immunobiology of human mesenchymal stem cells and future use in hematopoietic stem cell transplantation. Biol Blood Marrow Transplant 2005; 11(5): 321-34.

[29] Beyth S, Borovsky Z, Mevorach D, et al. Human mesenchymal stem cells alter antigen-presenting cell maturation and induce Tcell unresponsiveness. Blood 2005; 105(5): 2214-9.

[30] Dazzi F, Marelli-Berg FM. Mesenchymal stem cells for graftversus-host disease: close encounters with T cells. Eur J Immunol 2008; 38(6): 1479-82.

[31] Pittenger MF, Mackay AM, Beck SC, et al. Multilineage potential of adult human mesenchymal stem cells. Science 1999; 284(5411): 143-7.

[32] Ito T, Suzuki A, Okabe M, Imai E, Hori M. Application of bone marrow-derived stem cells in experimental nephrology. Exp Nephrol 2001; 9(6): 444-50.

[33] Fukuda K. Molecular characterization of regenerated cardiomyocytes derived from adult mesenchymal stem cells. Congenit Anom 2002; 42(1): 1-9.

[34] Johnstone B, Hering TM, Caplan AI, Goldberg VM, Yoo JU. In vitro chondrogenesis of bone marrow-derived mesenchymal progenitor cells. Exp Cell Res 1998; 238(1): 265-72.

[35] Qu-Petersen Z, Deasy B, Jankowski R, et al. Identification of a novel population of muscle stem cells in mice: potential for muscle regeneration. J Cell Biol 2002; 157(5): 851-64.

[36] Ferrari G, Cusella-De AG, Coletta M, et al. Muscle regeneration by bone marrow-derived myogenic progenitors. Science 1998; 279(5356): 1528-30.

[37] Azizi SA, Stokes D, Augelli BJ, DiGirolamo C, Prockop DJ. Engraftment and migration of human bone marrow stromal cells implanted in the brains of albino rats--similarities to astrocyte grafts. Proc Natl Acad Sci USA 1998; 95(7): 3908-13.

[38] Majumdar MK, Thiede MA, Mosca JD, Moorman M, Gerson SL. Phenotypic and functional comparison of cultures of marrowderived mesenchymal stem cells (MSCs) and stromal cells. J Cell Physiol 1998; 176(1): 57-66.

[39] Stott NS, Jiang TX, Chuong CM. Successive formative stages of precartilaginous mesenchymal condensations in vitro: modulation of cell adhesion by Wnt-7A and BMP-2. J Cell Physiol 1999; 180(3): 314-24.

[40] Wada MR, Inagawa-Ogashiwa M, Shimizu S, Yasumoto S, Hashimoto N. Generation of different fates from multipotent muscle stem cells. Development 2002; 129(12): 2987-95.

[41] Adachi N, Sato K, Usas A, et al. Muscle derived, cell based ex vivo gene therapy for treatment of full thickness articular cartilage defects. J Rheumatol 2002; 29(9): 1920-30.

[42] Bosch P, Musgrave DS, Lee JY, et al. Osteoprogenitor cells within skeletal muscle. J Orthop Res 2000; 18(6): 933-44.

[43] Young HE, Steele TA, Bray RA, et al. Human reserve pluripotent mesenchymal stem cells are present in the connective tissues of skeletal muscle and dermis derived from fetal, adult, and geriatric donors. Anat Rec 2001; 264(1): 51-62.

[44] Noth U, Osyczka AM, Tuli R, Hickok NJ, Danielson KG, Tuan RS. Multilineage mesenchymal differentiation potential of human trabecular bone-derived cells. J Orthop Res 2002; 20(5): 1060-9.

[45] Zuk PA, Zhu M, Mizuno H, et al. Multilineage cells from human adipose tissue: implications for cell-based therapies. Tissue Eng 2001; 7(2): 211-28.

[46] Shi S, Gronthos S, Chen S, et al. Bone formation by human postnatal bone marrow stromal stem cells is enhanced by telomerase expression. Nat Biotechnol 2002; 20(6): 587-91.

[47] Nakahara H, Goldberg VM, Caplan AI. Culture-expanded human periosteal-derived cells exhibit osteochondral potential in vivo. J Orthop Res 1991; 9(4): 465-76.

[48] Diefenderfer DL, Brighton CT. Microvascular pericytes express aggrecan message which is regulated by BMP-2. Biochem Biophys Res Commun 2000; 269(1): 172-8.

[49] Zvaifler NJ, Marinova-Mutafchieva L, Adams G, et al. Mesenchymal precursor cells in the blood of normal individuals. Arthritis Res 2000; 2(6): 477-88.
[50] De BC, Dell'Accio F, Luyten FP. Human periosteum-derived cells maintain phenotypic stability and chondrogenic potential throughout expansion regardless of donor age. Arthritis Rheum 2001; 44(1): 85-95.

[51] Raff M. Adult stem cell plasticity: fact or artifact? Annu Rev Cell Dev Biol 2003; 19: 1-22.

[52] Smith S, Neaves W, Teitelbaum S. Adult versus embryonic stem cells: treatments. Science 2007; 316(5830): 1422-3.

[53] Sart S, Schneider YJ, Agathos SN. Ear mesenchymal stem cells: an efficient adult multipotent cell population fit for rapid and scalable expansion. J Biotechnol 2009; 139(4): 291-9.

[54] Shi S, Bartold PM, Miura M, Seo BM, Robey PG, Gronthos S. The efficacy of mesenchymal stem cells to regenerate and repair dental structures. Orthod Craniofac Res 2005; 8(3): 191-9.

[55] Cenni E, Perut F, Baglio SR, Fiorentini E, Baldini N. Recent highlights on bone stem cells: A report from Bone Stem Cells 2009, and not only. J Cell Mol Med 2010.

[56] Getgood A, Brooks R, Fortier L, Rushton N. Articular cartilage tissue engineering: today's research, tomorrow's practice? J Bone Joint Surg Br 2009; 91(5): 565-76.

[57] Mitchell KJ, Pannerec A, Cadot B, et al. Identification and characterization of a non-satellite cell muscle resident progenitor during postnatal development. Nat Cell Biol 2010; 12(3): 257-66.

[58] Deans TL, Elisseeff JH. Stem cells in musculoskeletal engineered tissue. Curr Opin Biotechnol 2009; 20(5): 537-44.

[59] Qu Z, Mi S, Fang G. [Clinical study on treatment of bone nonunion with MSCs derived from human umbilical cord]. Zhongguo Xiu Fu Chong Jian Wai Ke Za Zhi 2009; 23(3): 345-7.

[60] Lee JY, Qu-Petersen Z, Cao B, et al. Clonal isolation of musclederived cells capable of enhancing muscle regeneration and bone healing. J Cell Biol 2000; 150(5): 1085-100.

[61] Scotti C, Tonnarelli B, Papadimitropoulos A, et al. Recapitulation of endochondral bone formation using human adult mesenchymal stem cells as a paradigm for developmental engineering. Proc Natl Acad Sci USA 2010; 107(16): 7251-6.

[62] Dezawa M, Ishikawa H, Itokazu $\mathrm{Y}$, et al. Bone marrow stromal cells generate muscle cells and repair muscle degeneration. Science 2005; 309(5732): 314-7.

[63] Tapp H, Deepe R, Ingram JA, Kuremsky M, Hanley EN, Jr., Gruber HE. Adipose-derived mesenchymal stem cells from the sand rat: transforming growth factor beta and 3D co-culture with human disc cells stimulate proteoglycan and collagen type I rich extracellular matrix. Arthritis Res Ther 2008; 10(4): R89.

[64] Noth U, Rackwitz L, Steinert AF, Tuan RS. Cell delivery therapeutics for musculoskeletal regeneration. Adv Drug Deliv Rev 2010; 62(7-8): 765-83.

[65] Quarto R, Mastrogiacomo M, Cancedda R, et al. Repair of large bone defects with the use of autologous bone marrow stromal cells. N Engl J Med 2001; 344(5): 385-6.

[66] Gangji V, Toungouz M, Hauzeur JP. Stem cell therapy for osteonecrosis of the femoral head. Expert Opin Biol Ther 2005; 5(4): 437-42.

[67] Funk JF, Matziolis G, Krocker D, Perka C. [Promotion of bone healing through clinical application of autologous periosteum derived stem cells in a case of atrophic non-union]. Z Orthop Unfall 2007; 145(6): 790-4.

[68] Phinney DG, Prockop DJ. Concise review: mesenchymal stem/multipotent stromal cells: the state of transdifferentiation and modes of tissue repair--current views. Stem Cells 2007; 25(11): 2896-902.

[69] Wang J, Kimura T, Asada R, et al. SCID-repopulating cell activity of human cord blood-derived. Blood 2003; 101(8): 2924-31.

[70] Mukherjee S, Raje N, Schoonmaker JA, et al. Pharmacologic targeting of a stem/progenitor population in vivo is associated with enhanced bone regeneration in mice. J Clin Invest 2008; 118(2): 491-504.

[71] Schipani E, Kronenberg HM. Adult mesenchymal stem cells. 2008.

[72] Tsutsumi S, Shimazu A, Miyazaki K, et al. Retention of multilineage differentiation potential of mesenchymal cells during proliferation in response to FGF. Biochem Biophys Res Commun 2001; 288(2): 413-9.

[73] Kulterer B, Friedl G, Jandrositz A, et al. Gene expression profiling of human mesenchymal stem cells derived from bone marrow during expansion and osteoblast differentiation. BMC Genomics 2007; 8: 70. 
[74] Pochampally RR, Smith JR, Ylostalo J, Prockop DJ. Serum deprivation of human marrow stromal cells (hMSCs) selects for a subpopulation of early progenitor cells with enhanced expression of OCT-4 and other embryonic genes. Blood 2004; 103(5): 1647-52.

[75] Hishikawa K, Miura S, Marumo T, et al. Gene expression profile of human mesenchymal stem cells during osteogenesis in threedimensional thermoreversible gelation polymer. Biochem Biophys Res Commun 2004; 317(4): 1103-7.
[76] Kratchmarova I, Blagoev B, Haack-Sorensen M, Kassem M, Mann M. Mechanism of divergent growth factor effects in mesenchymal stem cell differentiation. Science 2005; 308(5727): 1472-7.

[77] Song L, Webb NE, Song Y, Tuan RS. Identification and functional analysis of candidate genes regulating mesenchymal stem cell selfrenewal and multipotency. Stem Cells 2006; 24(7): 1707-18.

[78] Riminucci M, Saggio I, Robey PG, Bianco P. Fibrous dysplasia as a stem cell disease. J Bone Miner Res 2006; 21(Suppl 2): 125-31.

(C) Mafi et al.; Licensee Bentham Open.

This is an open access article licensed under the terms of the Creative Commons Attribution Non-Commercial License (http://creativecommons.org/licenses/by-nc/3.0/) which permits unrestricted, non-commercial use, distribution and reproduction in any medium, provided the work is properly cited. 